\title{
Correction to: Universal Material Constants for MultiStage Fatigue (MSF) Modeling of the Process-Structure-Property (PSP) Relations of $A 000,2000,5000$, and 7000 Series Aluminum Alloys
}

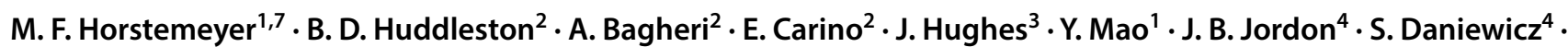
Cole Cauthen $^{4} \cdot$ Andrew Baker $^{5} \cdot$ Austin E. Mann $^{5} \cdot$ Steven Claves ${ }^{6} \cdot$ Matt Watson $^{6}$

Published online: 23 July 2020

(c) The Minerals, Metals \& Materials Society 2020

\section{Correction to: \\ Integrating Materials and Manufacturing Innovation \\ (2020) 9:157-180 \\ https://doi.org/10.1007/s40192-020-00175-3}

Readers should note the following error in this article:

The surname of one of the coauthors of the article, Steven Claves, is misspelled (as "Clayes") in the article as published.

The original article can be found online at https://doi.org/10.1007/ s40192-020-00175-3.

M. F. Horstemeyer

mhorstemeyer@liberty.edu

Predictive Design Technologies, Starkville, MS, USA

2 Mississippi State University, Starkville, MS, USA

3 Los Alamos National Laboratory, Santa Fe, NM, USA

4 University of Alabama, Tuscaloosa, AL, USA

5 Boeing Research and Technology, St. Louis, MO, USA

6 Arconic, Pittsburgh, PA, USA

7 Liberty University, Lynchburg, VA, USA 